\title{
DEFORMATION AND RECRYSTALLIZATION TEXTURES IN A C-Si-Mn-V DUAL PHASE STEEL
}

\author{
D. K. MONDAL \\ Department of Metallurgical Engineering, Regional Engineering College, \\ Durgapur-713209, India \\ R. K. RAY \\ Department of Metallurgical Engineering, Indian Institute of Technology, \\ Kanpur-208016, India
}

(Received 27 April, 1992; in final form 6 June, 1992)

\begin{abstract}
Dual phase structures were produced in a $\mathrm{C}-\mathrm{Si}-\mathrm{Mn}-\mathrm{V}$ steel from both ferrite-pearlite and martensitic structures by intercritical annealing at $750^{\circ} \mathrm{C}$ and $810^{\circ} \mathrm{C}$. Samples with different distributions of ferrite and martensite were cold rolled $60 \%$ and then recrystallized at $650^{\circ} \mathrm{C}$ and $800^{\circ} \mathrm{C}$ for different lengths of time. Texture measurements were carried out on the cold rolled as well as recrystallized materials using both the conventional pole-figure and ODF (Orientation Distribution Function) methods. The results indicated the presence of a reasonably strong $\langle 111\rangle \|$ ND fibre in the cold deformed alloy. The textures in the recrystallized condition were found to be basically similar to the ones for the corresponding cold deformed materials, with the difference that the pole densities were somewhat weaker in the former. A weak $\{11,11,4\}$ fibre and a weak and incomplete $\{337\}$ fibre have also been observed in both the cold deformed and recrystallized materials. Samples recrystallized at the lower temperature of $650^{\circ} \mathrm{C}$ exhibited a sharper $\{111\}$ texture as compared to the $800^{\circ} \mathrm{C}$ annealed materials and this difference in texture intensities were perceptibly reflected in the corresponding $r$-values.
\end{abstract}

KEY WORDS Dual phase steel, ODF-analysis, deformation texture, recrystallization texture.

\section{INTRODUCTION}

Dual phase microstructures can be obtained practically in all sheet steels by reheating them in the intercritical range followed by cooling to produce a ferrite-martensite phase mixture. Alternatively, these can be produced directly from the rolling heat in hot strip mills. The intercritically annealed dual phase steels are found to exhibit both $\{111\}$ and $\{337\}$-type fibre texture (Ray, 1984) along with some minor components such as $\{310\}\langle 001\rangle$ and $\{110\}\langle 001\rangle$. On the other hand, texture components of the type $\{111\}\langle 011\rangle,\{111\}\langle 112\rangle$ and $\{112\}\langle 110\rangle$ have been reported in hot rolled dual phase steels (Bunge, Vlad and Kopp, 1984).

The attainment of superior deep drawability in a sheet steel can be linked to the ease of nucleation and growth of $\{111\}$ oriented grains in the materials (Mishra and Därmann, 1982). Preliminary work carried out on a C-Mn-Si-V dual phase steel (Ray, 1985) showed that a reasonably strong $\{111\}\langle 112\rangle$ and a weak $\{111\}\langle 110\rangle$ texture component develops on cold rolling, and these do not 
Table 1 Composition of the steel in wt \%

\begin{tabular}{lllllll}
\hline Elements & $\mathrm{C}$ & $\mathrm{Mn}$ & $\mathrm{Si}$ & $\mathrm{S}$ & $\mathrm{P}$ & $\mathrm{V}$ \\
\hline Contents & 0.12 & 1.51 & 1.47 & 0.021 & 0.016 & 0.09 \\
\hline
\end{tabular}

undergo much change upon subsequent annealing. The present work was undertaken to make a detailed study of the response of the above dual phase steel to the processes of cold deformation and subsequent recrystallization, and to follow particularly the development of the $\{111\}$ fibre texture. The texture studies were supplemented with detailed microstructural observation.

\section{EXPERIMENTAL PROCEDURE}

The chemical composition of the steel used in the present investigation is given in Table 1. In this steel dual phase structures were produced in two different ways: (i) samples with a ferrite-pearlite initial structure, obtained by air cooling [AC] from a homogeneous temperature of $910^{\circ} \mathrm{C}$, were intercritically annealed at $750^{\circ} \mathrm{C}$ and $810^{\circ} \mathrm{C}$, followed by water quenching [WQ]; (ii) samples with a martensitic initial structure, obtained by water quenching [WQ] from the same homogenization temperature, were intercritically annealed at $750^{\circ} \mathrm{C}$ and $810^{\circ} \mathrm{C}$, followed by

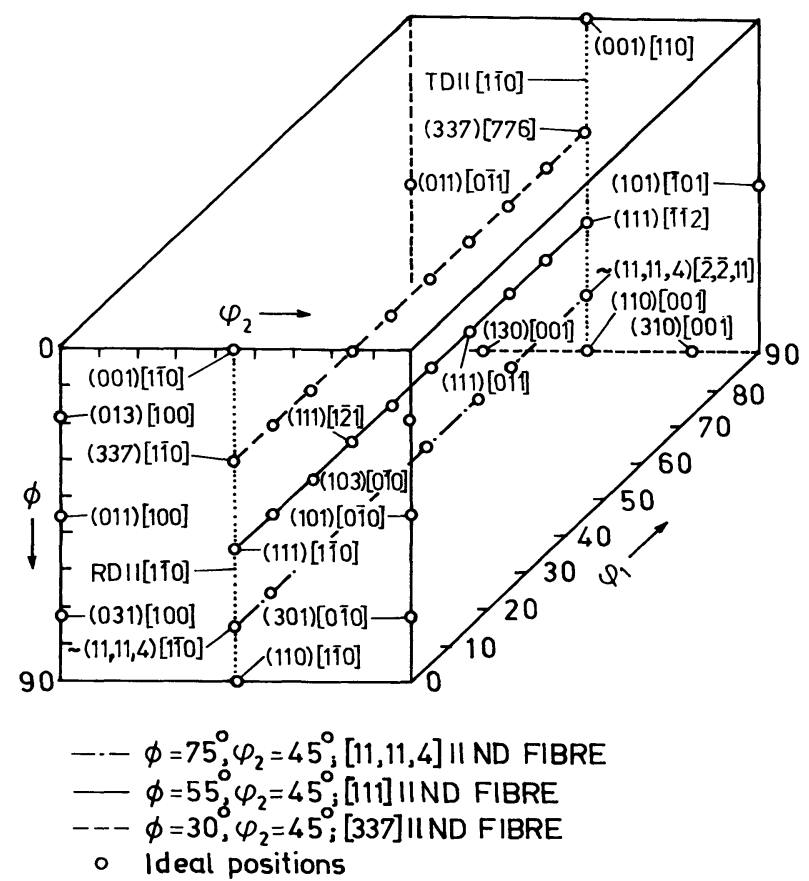

Figure 1 Three dimensional Euler space showing the locations of ideal orientations. 
water quenching [WQ]. Samples prepared by treatments (i) and (ii) have been designated as $\mathrm{AC} / \mathrm{WQ}$ and $\mathrm{WQ} / \mathrm{WQ}$ respectively. All steel samples, thus prepared, such as AC750/WQ, AC810/WQ, WQ750/WQ and WQ810/WQ were cold rolled $60 \%$ at room temperature. The cold deformed alloys were further subjected to recrystallization anneal at $650^{\circ} \mathrm{C}$ and $800^{\circ} \mathrm{C}$ for various lengths of time, till full recrystallization was achieved. Structural characterization of the initial material, the deformed and the recrystallized alloy was carried out by both optical and transmission electron microscopy (TEM) using transverse sections of the specimens. Initial texture measurements were carried out by determining the (110) pole-figures from flat samples, using the Schulz reflection method (Cullity, 1978). Finally, incomplete pole-figure (Schulz, 1949) intensity data were obtained for $\{110\},\{200\}$ and $\{112\}$ reflections using a Lücke automated texture goniometer system (Alam, Mengelberg and Lücke, 1967; Kobe and Schuon, 1973). Three dimensional orientation distribution functions (ODF's) were calculated from these pole-figure data in the usual manner. Figure 1 represents an isometric view of the three dimensional orientation space defined by the angles $\varphi_{1}, \phi, \varphi_{2}$. The positions of a few important ideal orientations are also shown therein.

\section{RESULTS}

\section{Starting Materials}

Optical micrographs of the four different dual phase structures produced in the experimental steel are given in Figure 2(a-d), showing different distributions of ferrite and martensite corresponding to different initial heat treatments. Volume fractions of ferrite and martensite, measured on the four dual phase structures, are reported in Table 2 . The TEM studies did not reveal any major difference in the structural details of the phases, as a function of the initial heat treatment. Figure 3 shows a typical transmission electron microstructure of the starting material, showing martensitic areas in a matrix of ferrite.

\section{Cold Rolled Materials}

The (110) pole-figures for the cold rolled alloy with different initial heat treatments are given in Figure 4. All these pole-figures show a moderately strong $\{111\}\langle 112\rangle$ texture component with the maximum intensities varying from $2 \times$ random to $3 \times$ random. The strongest texture has been obtained for the material AC750/WQ. The above pole-figures also show the presence of a minor $\{111\}\langle 110\rangle$ component, the intensities of which remain practically unchanged with different initial heat treatments.

To obtain detailed textural informations, ODF plots were prepared from all the cold rolled materials. $\varphi_{1}$ sections $\left(0^{\circ}, 5^{\circ}, 10^{\circ}, \ldots, 90^{\circ}\right)$ of such plots are shown typically for the AC/WQ materials in Figures 5(a) and (b). Intensities of a few maxima in the above plots are indicated at appropriate places. It is clearly evident from these ODF's that the intensity levels are not at all significantly high, as was also observed in case of the corresponding pole-figures. A slightly higher value of $f(g)_{\max }$ is found for the material intercritically annealed at the lower temperature 

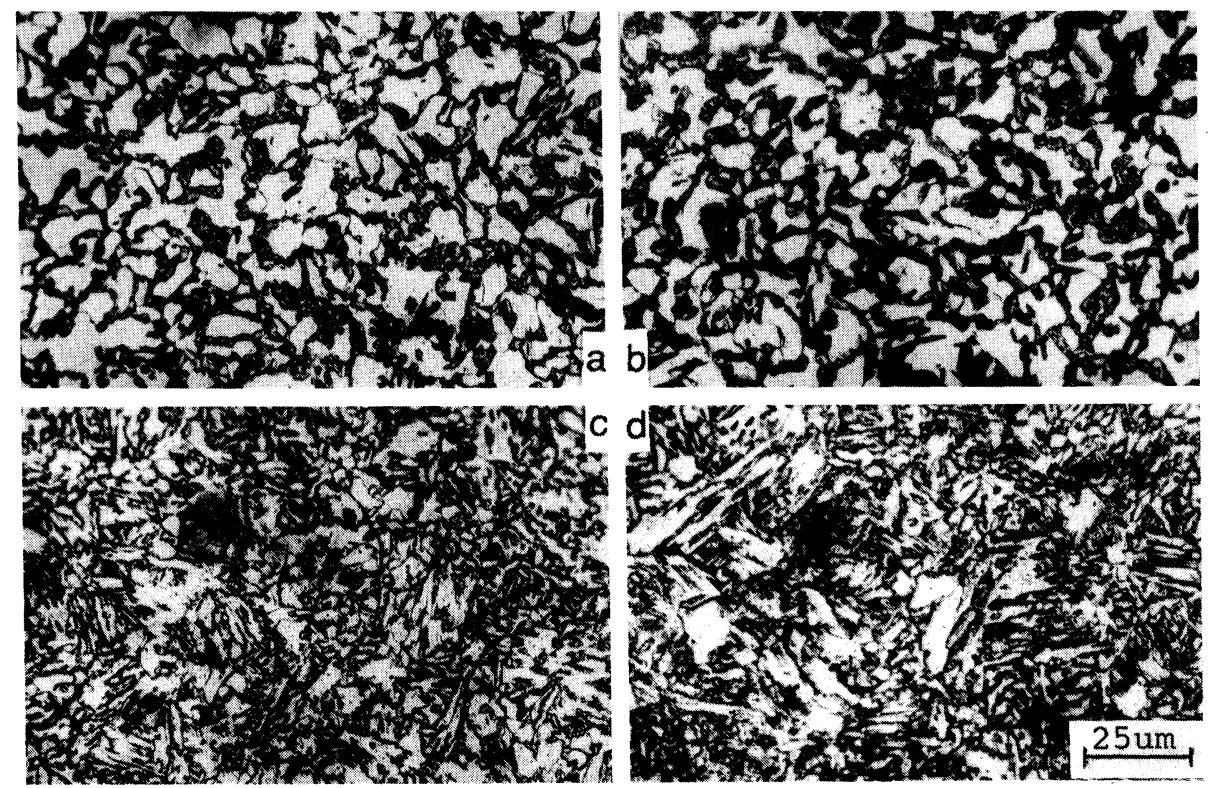

Figure 2 Optical micrographs of the alloy: (a) AC750/WQ, (b) AC810/WQ, (c) WQ750/WQ, (d) WQ810/WQ.

of $750^{\circ} \mathrm{C}$ as compared to the higher temperature of $810^{\circ} \mathrm{C}$. Features similar to these were also observed in the ODF's of the WQ/WQ materials.

The ODF's presented in Figure 5 show a number of peak-type components in each plot. Euler angles (read out from the relevant computer print-outs) and the corresponding orientations for such peak-type components were determined (see Figure 1). The ODF plots of the cold rolled materials show a number of major texture components such as $\{111\}\langle 110\rangle$ and $\{111\}\langle 112\rangle$ along with some minor ones of the type $\{337\}\langle 110\rangle,\{337\}\langle 776\rangle,\{112\}\langle 111\rangle$ and $\{112\}\langle 110\rangle$. To verify the presence of any fibre texture, the intensity values, $f(g)$, are plotted as a function of $\phi$ along two lines in the Euler space, namely, (a) for the section $\varphi_{1}=0^{\circ}$ along $\varphi_{2}=45^{\circ}$ and (b) for the section $\varphi_{1}=90^{\circ}$ along $\varphi_{2}=45^{\circ}$. Plots of this kind are shown typically for the AC/WQ materials in Figure 6. It is clearly

Table 2 Volume percent ferrite and martensite for dual phase heat treated (a) and $800^{\circ} \mathrm{C}$ recrystallization annealed samples (b)

\begin{tabular}{|c|c|c|c|c|}
\hline \multirow[t]{2}{*}{$\begin{array}{l}\text { Sample } \\
\text { designation }\end{array}$} & \multicolumn{2}{|c|}{$\begin{array}{c}\text { (a) Dual phase heat } \\
\text { treatment }\end{array}$} & \multicolumn{2}{|c|}{$\begin{array}{c}\text { (b) } 800^{\circ} \text { C-recrystallization } \\
\text { Anneal }\end{array}$} \\
\hline & $\%$ Ferrite & $\%$ Martensite & $\%$ Ferrite & $\%$ Martensite \\
\hline AC750/WQ & 70 & 30 & 54 & 46 \\
\hline AC810/WQ & 49 & 51 & 40 & 60 \\
\hline WQ750/WQ & 57 & 43 & 42 & 58 \\
\hline WQ810/WQ & 46 & 54 & 34 & 66 \\
\hline
\end{tabular}




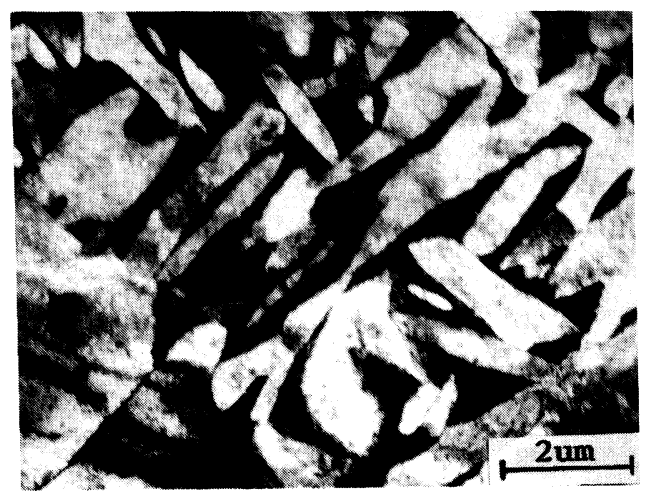

Figure 3 Transmission electron micrograph from the alloy with initial heat treatment AC810/WQ.

seen from this figure that two distinct peaks at $\phi=55^{\circ}$ and $\phi=75^{\circ}$, were obtained in the AC750/WQ material for both the $\varphi_{1} / \varphi_{2}$ sections. The peak at $\phi=55^{\circ}$ is much sharper than the one at $\phi=75^{\circ}$. The plot for the AC810/WQ material shows a reasonably intense but flat plateau centred about $\phi=30^{\circ}$ and a weak peak at $\phi=75^{\circ}$ in the $\varphi_{1}=0^{\circ} / \varphi_{2}=45^{\circ}$ section. On the other hand, the plot for the $\varphi_{1}=90^{\circ} / \varphi_{2}=45^{\circ}$ section shows two weak peaks at $\phi=55^{\circ}$ and $\phi=75^{\circ}$. Similar behaviour was observed in the relevant plots of the WQ/WQ materials. The peak positions at $\phi=30^{\circ}, 55^{\circ}$ and $75^{\circ}$ in the above two sections correspond to the orientations $\sim\{337\}\langle\mathrm{uvw}\rangle, \quad\{111\}\langle\mathrm{uvw}\rangle$ and $\{11,11,4\}\langle\mathrm{uvw}\rangle$ respectively. The possibilities of having fibre textures of the type $\{337\},\{111\}$ and $\{11,11,4\}$ were further checked by plotting $f(g)$ against $\varphi_{1}\left(=0^{\circ}\right.$ to $\left.90^{\circ}\right)$ for (a) $\phi=30^{\circ}, \varphi_{2}=45^{\circ}$, (b) $\phi=55^{\circ}, \varphi_{2}=45^{\circ}$ and (c) $\phi=75^{\circ}, \varphi_{2}=45^{\circ}$. The relevant plots for the $\mathrm{AC} / \mathrm{WQ}$ materials are presented in Figure 7 which clearly show the presence of a reasonably strong $\{111\}$ fibre texture in both the AC750/WQ and AC810/WQ samples. This fibre is nearly twice as intense for the AC750/WQ material as compared to the AC810/WQ. Figure 7 also shows the presence of a $\{11,11,4\}$ fibre of rather low intensity, while $\{337\}\langle u v w\rangle$ orientations form a very weak and incomplete fibre in both the materials.

Optical microstructures of all the four cold rolled materials look quite similar, showing ferrite and martensitic areas, deformed and flattened out in the direction of rolling. Deformation bands are also noticed in some parts of the ferrite field. Figure 8 shows a typical transmission electron micrograph of the cold rolled
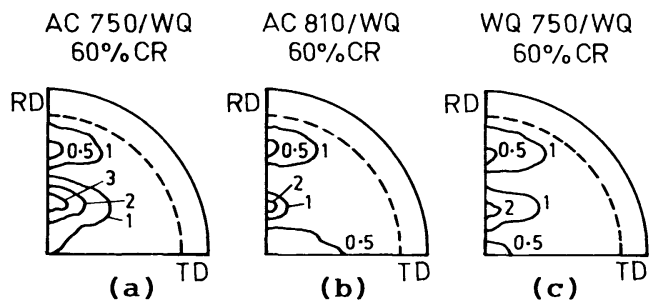

\section{WQ $810 / W Q$ $60 \% \mathrm{CR}$}

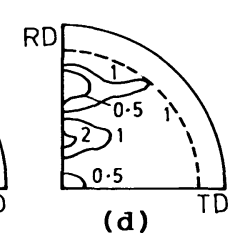

Figure 4 (110) Pole-figures of the cold worked alloy with different initial heat treatments. 

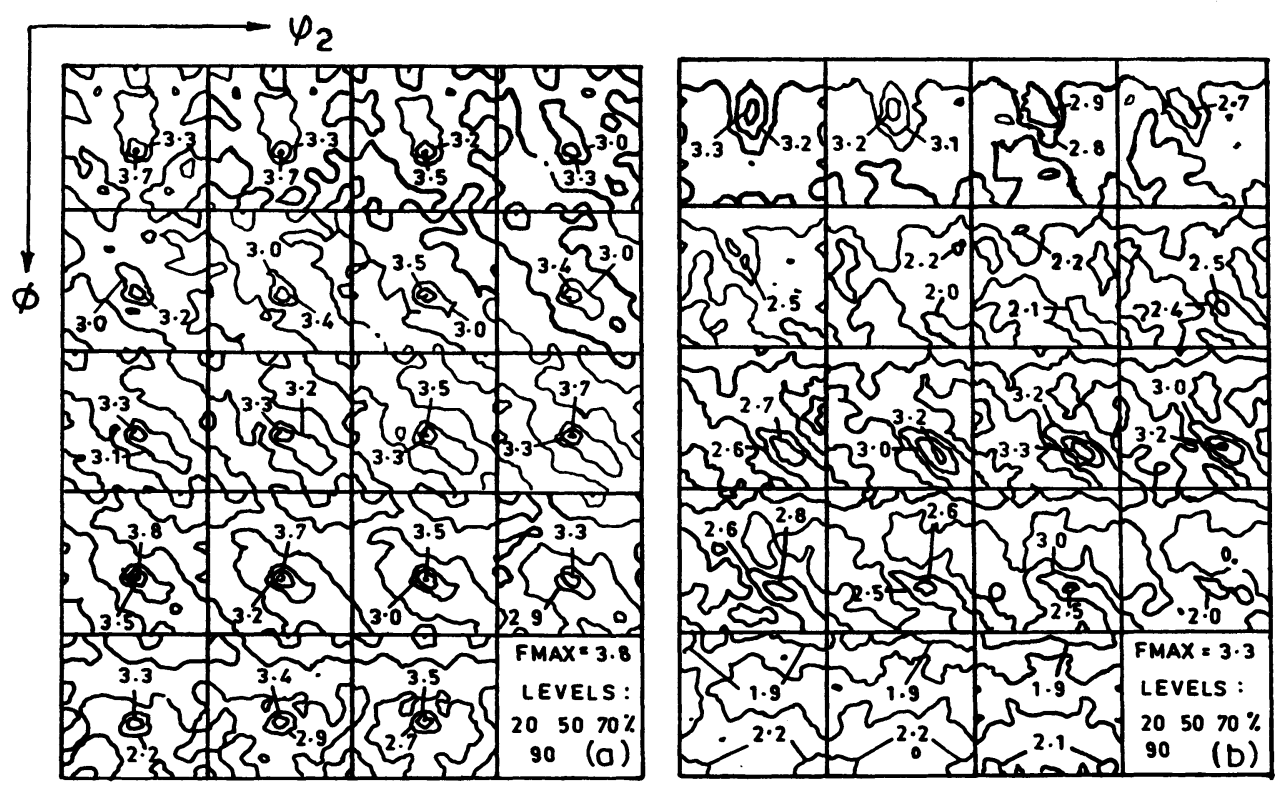

Figure 5 O.D.F.'s showing $\varphi_{1}$ sections for: (a) AC750/WQ cold rolled 60\%, (b) AC810/WQ cold rolled $60 \%$.

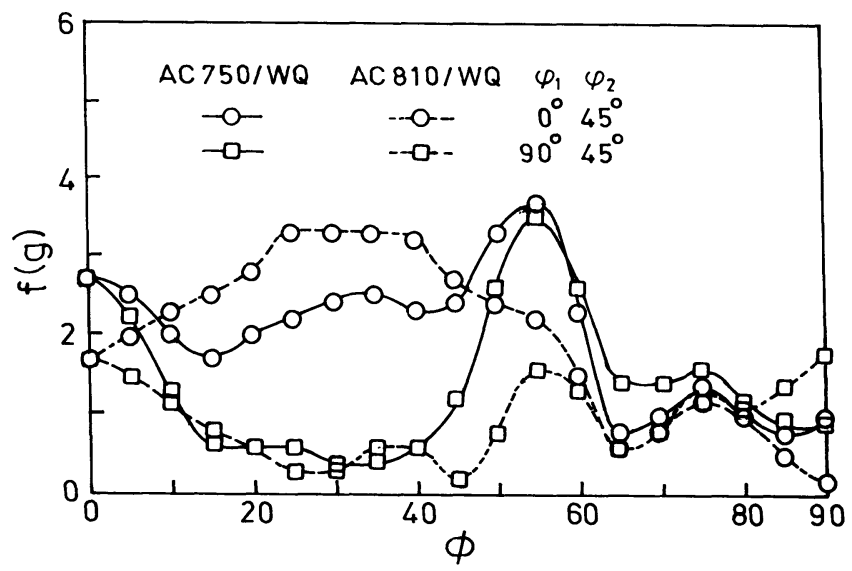

Figure 6 Variation of $f(g)$ with $\phi$ along different $\varphi_{1} / \varphi_{2}$ lines for the cold rolled materials with AC/WQ treatment. 


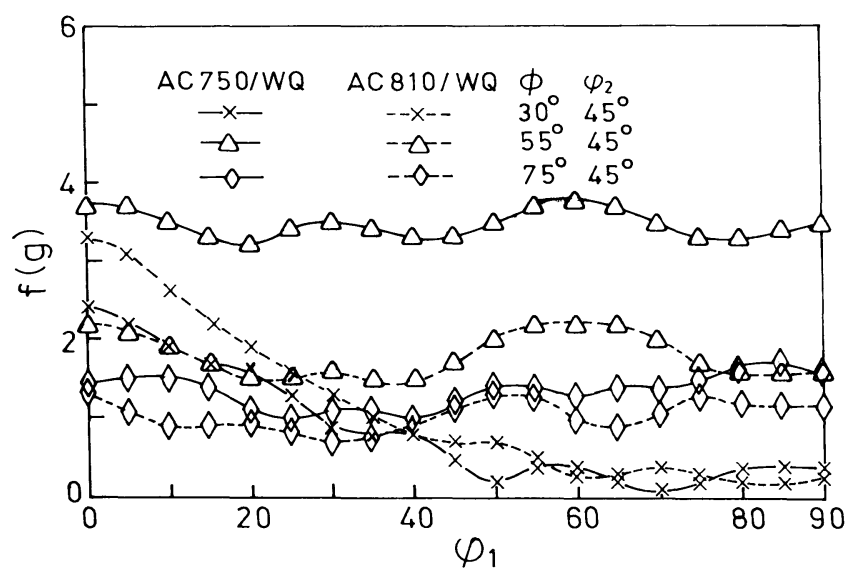

Figure 7 Variation of $f(g)$ with $\varphi_{1}$ along different $\phi / \varphi_{2}$ lines for the cold rolled materials with AC/WQ treatment.

material, exhibiting heavily deformed and elongated cells of ferrite with high dislocation density as well as ribbons of martensite which have clearly undergone some amount of plastic deformation.

\section{Recrystallized Materials}

As shown in Figures $9(a-h)$, the (110) pole-figures of the recrystallized samples are very much similar to the ones for the corresponding cold rolled materials (see Figure 4) with respect to the positions of the texture maxima. However, the pole densities get reduced drastically after recrystallization. As a result, the annealing textures are found to be nearly random in some cases. The ODF plots from the recrystallized materials shown typically for the AC/WQ samples in Figure 10, clearly indicate that the $f(g)_{\text {max }}$-value is lowered when recrystallization is carried out at the higher temperature. Again, $f(g)_{\max }$ has been found to be slightly higher for the materials intercritically annealed at the higher temperature of $810^{\circ} \mathrm{C}$. In

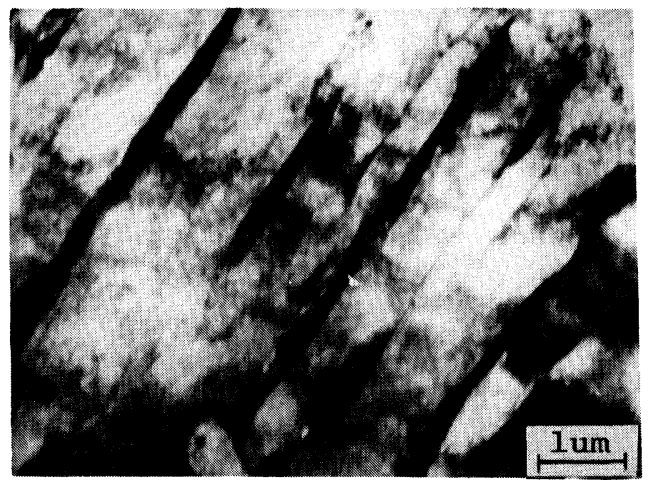

Figure 8 Transmission electron micrograph of the cold rolled alloy with initial heat treatment AC810/WQ. 


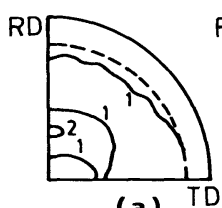

(a)

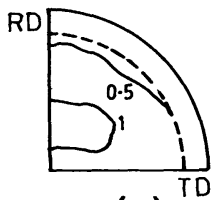

(e)
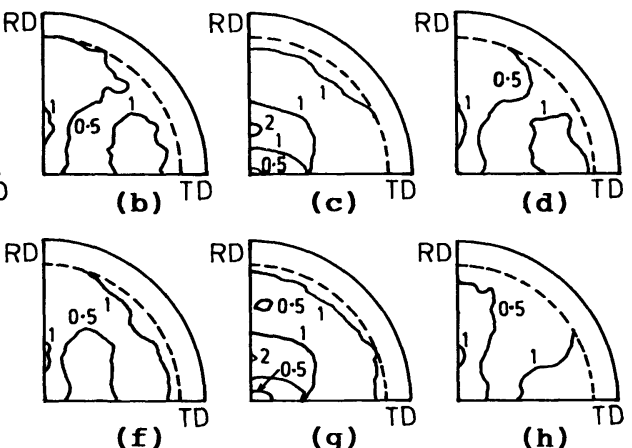

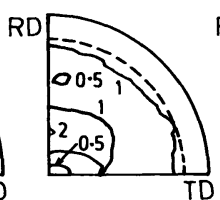

(g)

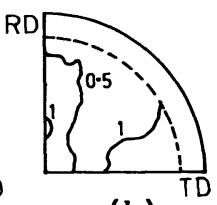

(h)

Figure 9 (110) pole-figures of the recrystallized alloy: AC750/WQ (a) Recry. $650^{\circ} \mathrm{C} / 60 \mathrm{~S}$, (b) Recry. $800^{\circ} \mathrm{C} / 10 \mathrm{~S}$. AC810/WQ (c) Recry. $650^{\circ} \mathrm{C} / 60 \mathrm{~S}$, (d) Recry. $800^{\circ} \mathrm{C} / 10 \mathrm{~S}$. WQ750/WQ (e) Recry. $650^{\circ} \mathrm{C} / 60 \mathrm{~S}$, (f) Recry. $800^{\circ} \mathrm{C} / 10 \mathrm{~S}$. WQ810/WQ (g) Recry. $650^{\circ} \mathrm{C} / 60 \mathrm{~S}$, (h) Recry. $800^{\circ} \mathrm{C} / 10 \mathrm{~S}$.

fact, no significant variation in $f(g)_{\max }$ has been observed as a function of the nature of the initial heat treatment, namely AC/WQ and WQ/WQ. A comparison of Figure 5 and Figure $\mathbf{1 0}$ demonstrates that, so far as the peak-type components are concerned, there is not much significant difference in the deformation and the recrystallization textures.

In the same manner as described earlier for the deformation texture ODF's, the possibility of having fibre texture in the recrystallized materials has been checked by plotting $f(g)$ against $\phi$ along different $\varphi_{1} / \varphi_{2}$ lines. Such plots for the AC/WQ materials are shown in Figure 11. An examination of these plots reveals that for the materials recrystallized at $650^{\circ} \mathrm{C}$, reasonably sharp peaks appear at $\phi=55^{\circ}$ in both the sections $\varphi_{1}=0^{\circ}, \varphi_{2}=45^{\circ}$ and $\varphi_{1}=90^{\circ}, \varphi_{2}=45^{\circ}$. In addition to this, shorter peaks are noticed at $\phi=75^{\circ}$ in both the sections and flat plateaus of high intensity, centred between $\phi=25^{\circ}$ and $30^{\circ}$ in the $\varphi_{1}=0^{\circ}, \varphi_{2}=45^{\circ}$ section. Materials recrystallized at the higher temperature of $800^{\circ} \mathrm{C}$ also show similar variations in $f(g)$ with the difference that the pole densities here are decidedly much weaker. Finally, the plots of $f(g)$ versus $\varphi_{1}\left(=0^{\circ}\right.$ to $\left.90^{\circ}\right)$ for (a) $\phi=30^{\circ}$ and $\varphi_{2}=45^{\circ}$, (b) $\phi=55^{\circ}$ and $\varphi_{2}=45^{\circ}$ and (c) $\phi=75^{\circ}$ and $\varphi_{2}=45^{\circ}$, are shown typically for all the recrystallized $\mathrm{AC} / \mathrm{WQ}$ materials in Figures 12(a) and (b). It is apparent from these plots that reasonably strong $\{111\}$-fibre is developed in both the AC750/WQ and AC810/WQ materials recrystallized at $650^{\circ} \mathrm{C}$. This fibre is found to be comparatively weak for the higher recrystallization temperature of $800^{\circ} \mathrm{C}$. No perfect fibre with respect to the orientations $\{337\}\langle u v w\rangle$ and $\{11,11,4\}\langle u v w\rangle$, are observed in these recrystallized samples. The above behaviour has been found to be rather similar for the WQ/WQ materials also.

The textural difference between the two sets of samples, recrystallization annealed at the two different temperatures of $650^{\circ} \mathrm{C}$ and $800^{\circ} \mathrm{C}$ are reflected pretty well in the corresponding $r$-value plots (see Figure 13). These values were calculated theoretically on the basis of $\{h k l\}\langle 111\rangle$ pencil glide from the experimentally determined ODF's using a computer programme developed by Bunge et al. (Bunge and Vlad, 1981). As expected, a higher intensity of the $\{111\}$ texture corresponds with a higher value of the Lankford parameter, $r$. 

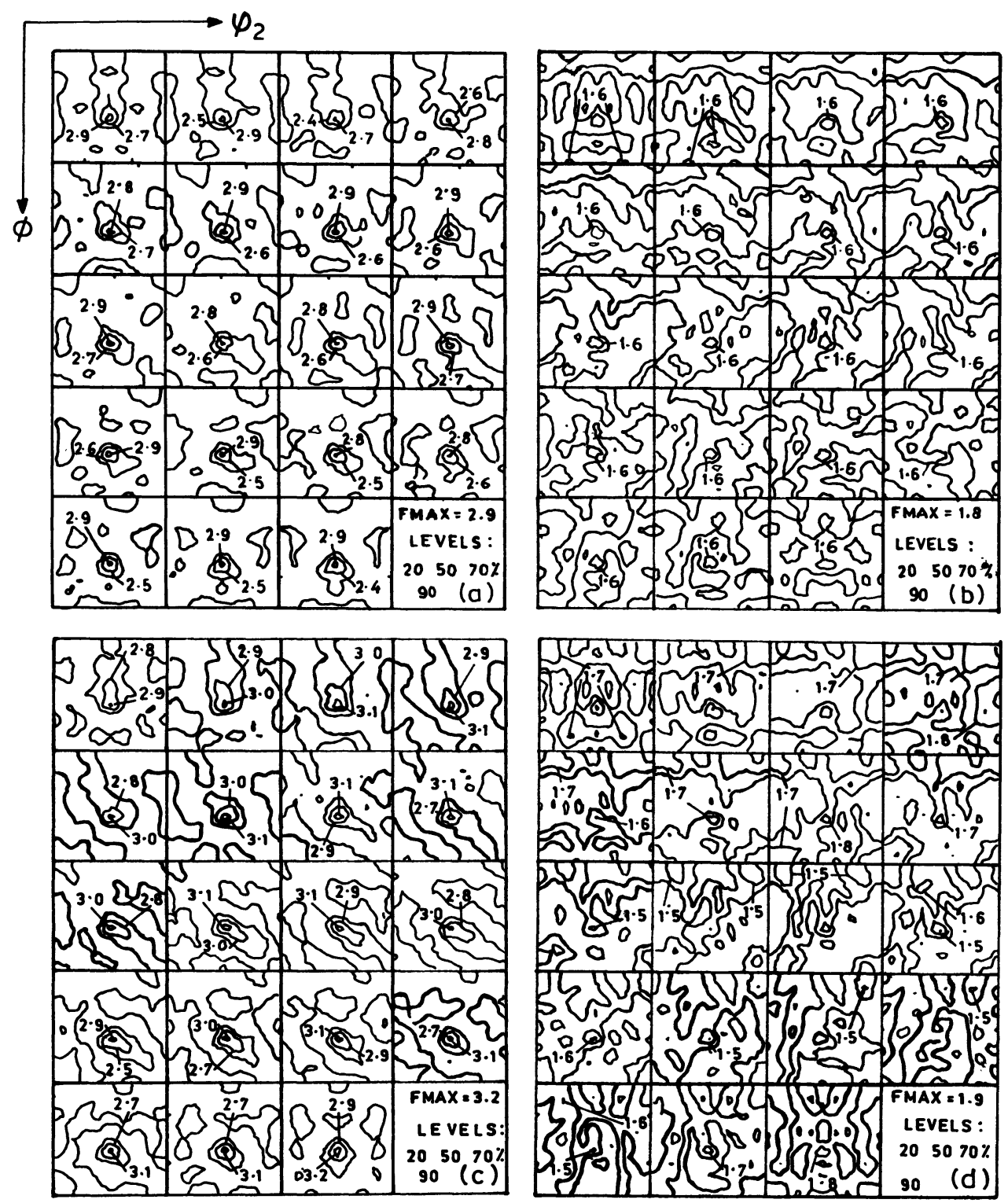

Figure 10 O.D.F.'s showing $\varphi_{1}$ sections for AC750/WQ (a) Recry. $650^{\circ} \mathrm{C} / 60 \mathrm{~S}$,, (b) Recry. $800^{\circ} \mathrm{C} / 10 \mathrm{~S}$. AC810/WQ (c) Recry. $650^{\circ} \mathrm{C} / 60 \mathrm{~S}$, (d) Recry. $800^{\circ} \mathrm{C} / 10 \mathrm{~S}$. 


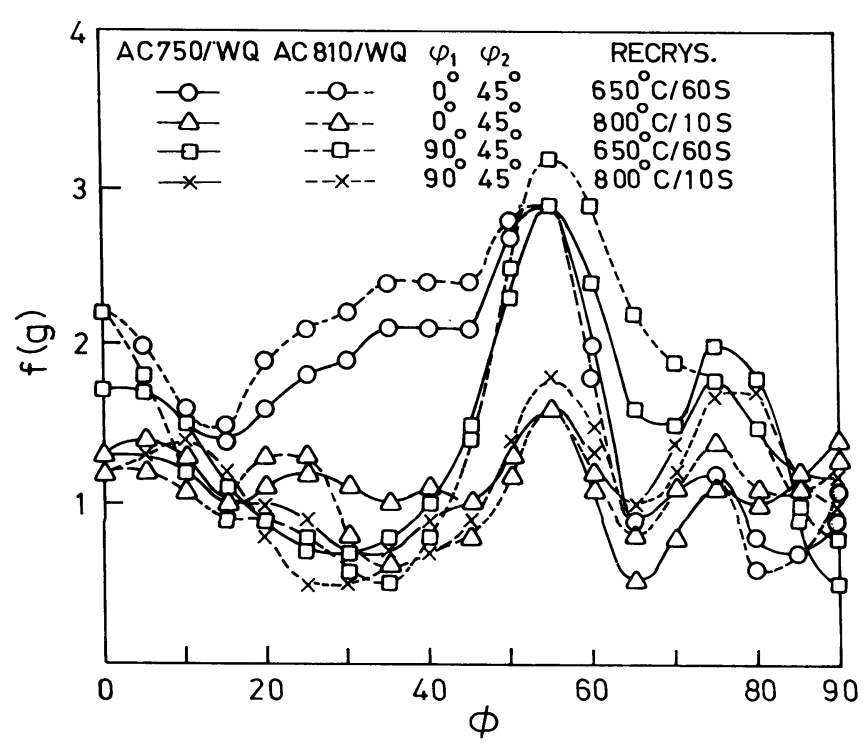

Figure 11 Variation of $f(g)$ with $\phi$ along different $\varphi_{1} / \varphi_{2}$ lines for the recrystallized materials with initial heat treatment $\mathrm{AC} / \mathrm{WQ}$.

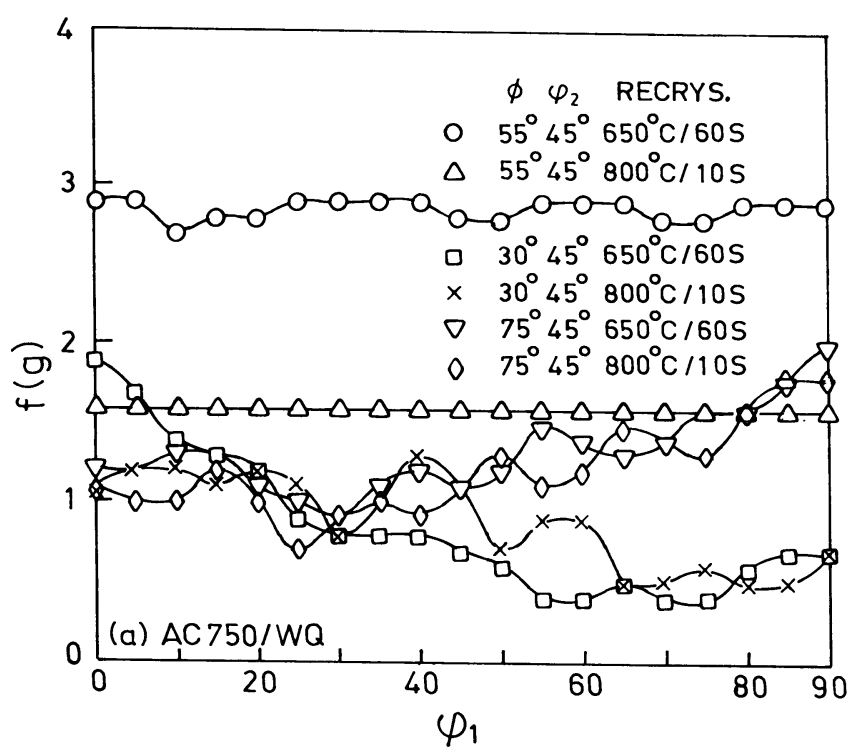

Figure 12 Variation of $f(g)$ with $\varphi_{1}$ along different $\phi / \varphi_{2}$ lines for the recrystallized materials with initial heat treatments: (a) AC750/WQ and (b) AC810/WQ. 


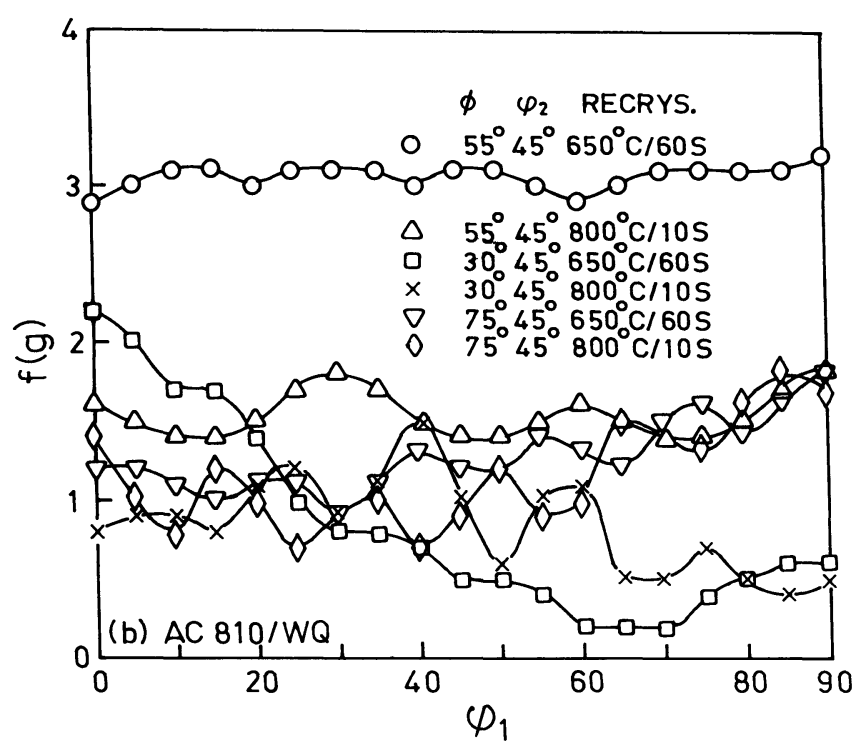

Figure 12 (Continued).

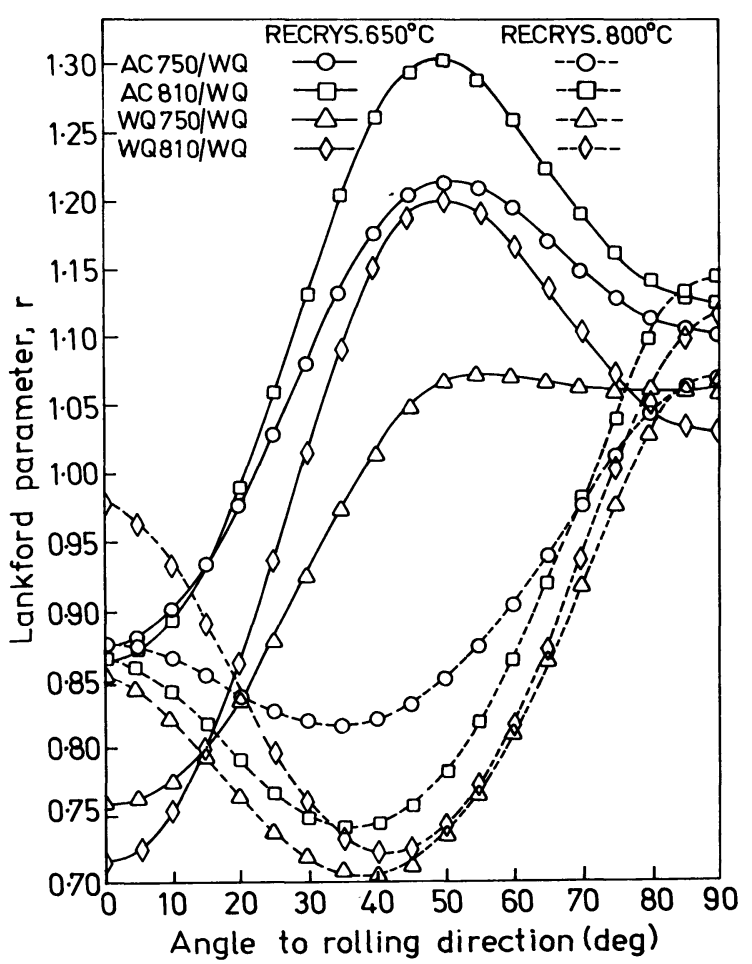

Figure 13 Variation in the Lankford strain ratio $r$ with angle from the rolling direction for the recrystallized materials having initial treatments $A C / W Q$ and WQ/WQ. 

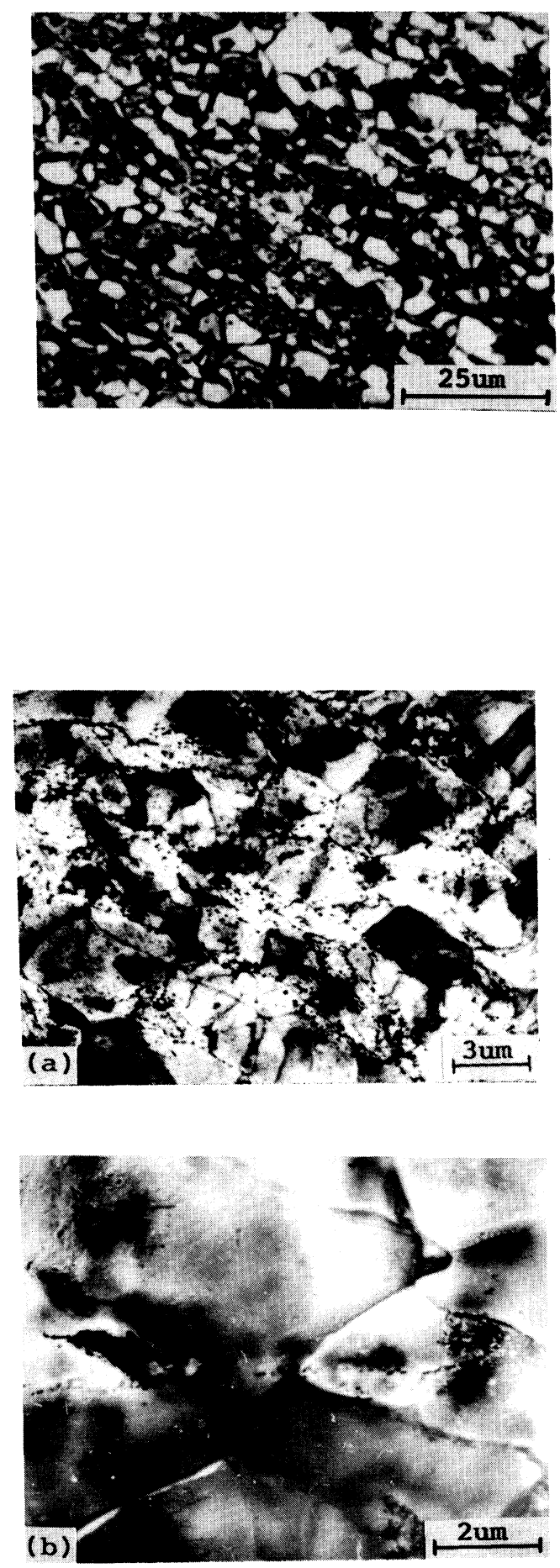

Figure 14 Optical micrograph of the alloy with initial heat treatment WO810/WQ and recrystallization annealed at $800^{\circ} \mathrm{C}$ for 10 seconds.
Figure 15 Transmission electron micrographs of the recrystallized alloy: (a) WQ750/WQ Recry. $650^{\circ} \mathrm{C} / 60 \mathrm{~S}$,, (b) WQ750/WQ Recry. $800^{\circ} \mathrm{C} / 10 \mathrm{~S}$. 
A typical optical micrograph of the alloy, after recrystallization at $800^{\circ} \mathrm{C}$, is shown in Figure 14. This micrograph clearly shows a duplex structure consisting of ferrite and martensite areas. No significant difference could be noticed in the electron micrographs of the recrystallized samples as function of prior heat treatment, excepting that the ferrite grains appeared to be somewhat larger in size in the materials subjected to $\mathrm{AC} / \mathrm{WQ}$ treatment as compared to WQ/WQ treatment. A typical electron microstructure of the alloy (Figure 15a) recrystallized at $650^{\circ} \mathrm{C}$ shows ferrite and martensite grains with a profusion of fine precipitate particles along grain boundaries as well as within the ferrite grains. In constrast to this behaviour, the ferrite grains in the material recrystallized at $800^{\circ} \mathrm{C}$ (Figure $15 \mathrm{~b}$ ) show only very few precipitate particles within.

\section{DISCUSSION}

The foregoing clearly shows that there is practically no significant variation in either the deformation or the recrystallization textures of the experimental dual phase steel as a function of the initial heat treatment. The deformation texture consists essentially of a reasonably strong $\{111\}$ fibre together with a rather weak $\{11,11,4\}$ and a very weak and incomplete $\{337\}$ fibres. Using the model of Dillamore and Katoh (1974) it has been suggested that the stable end orientations of the rolling texture for a BCC metal (Hutchinson and Katoh, 1974), like iron, will be $(112)[110]$ and $(11,11,8)[\overline{4}, \overline{4}, 11]$. It is expected that the actual texture will be spread around these stable ideal orientations. The orientation (112) [110] is only $4^{\circ}$ away, in the Euler space, from the orientation (337) [110] which is one of the components of the weak $\langle 337\rangle \| N D$ fibre texture found in the deformed alloy. The ideal orientation $(11,11,8)[\overline{4}, \overline{4}, 11]$ has the Euler angles $\varphi_{1}=90^{\circ}$, $\phi=63^{\circ}$ and $\varphi_{2}=45^{\circ}$. It may be noted here that the component $(11,11,4)$ $[\overline{2}, \overline{2}, 11]$ which forms a part of the rather weak $\{11,11,4\}$-type of fibre texture in the experimental alloy, corresponds to the Euler angles $\varphi_{1}=90^{\circ}, \phi=76^{\circ}$ and $\varphi_{2}=45^{\circ}$. Thus the above two orientations are about $13^{\circ}$ apart in the Euler space and hence the observed orientation $(11,11,4)[\overline{2}, \overline{2}, 11]$ may be considered to be within the spread around the theoretical ideal orientation, namely, $(11,11,8)$ $[\overline{4}, \overline{4}, 11]$. The rolling texture components obtained for the experimental dual phase steel are not very different from typical rolling textures of iron and steels (Bunge, Vlad and Kopp, 1984; Hu, 1980).

In general, the recrystallization textures in the present alloy have been found to be rather similar to the corresponding deformation textures, so far as the locations, in the orientation space, of most of the major and minor orientation components are concerned. However, the intensity levels of the texture components in the recrystallized condition are decidedly lower than in the deformed condition. This can be explained by assuming an in-situ recrystallization process, where the recrystallized grains originate from deformed regions of the same or nearly the same orientation, followed by a limited growth. Such a process will lead to the formation of rather fine and uniform grains. Figure 14 clearly indicates such a possibility in the present alloy.

The most interesting aspect of the textural results is the formation of a reasonably strong $\langle 111\rangle \| N D$ fibre texture after deformation (Figure 7 ). This fibre 
is retained after the recrystallization process (Figures 12a and $b$ ). The intensities of the $\{111\}\langle u v w\rangle$ components have been found to be consistently higher at the lower temperature of recrystallization, namely, $650^{\circ} \mathrm{C}$ than at the higher temperature of recrystallization, which is $800^{\circ} \mathrm{C}$. The $650^{\circ} \mathrm{C}$ anneal should not produce any change in the original amounts of martensite in the dual phase steel samples, since here recrystallization takes place essentially in the $\alpha$-region. In contrast, the $800^{\circ} \mathrm{C}$ anneal takes place in the $\alpha+\gamma$ intercritical range where the amounts of austenite in the samples will increase as annealing progresses. There will therefore be a corresponding increase in the amounts of martensite in the resulting dual phase structures after recrystallization is completed. This is quite apparent from Table II which is also showing the volume percent mertensite in the alloy after full recrystallization at $800^{\circ} \mathrm{C}$. This phenomenon is expected to have a serious implication in that the volume of recrystallizing ferrite in the sample annealed at the higher temperature of $800^{\circ} \mathrm{C}$ will be less than that in the sample annealed at the lower temperature of $650^{\circ} \mathrm{C}$. Thus, the intensity of the \{111\} texture, which is obtained essentially from the ferrite phase, will tend to be less sharp in the former as compared to that in the latter. This is what has been noticed in all the samples in the present case.

It may be recalled here that the electron microstructure of the alloy, recrystallized at the lower temperature of $650^{\circ} \mathrm{C}$ (Figure $15 \mathrm{a}$ ) shows a dense precipitation of fine particles, whose identity could not be established. There is a drastic decrease in the density of such precipitate particles when the alloy is recrystallized at the higher temperature of $800^{\circ} \mathrm{C}$ (Figure $15 \mathrm{~b}$ ). Finely dispersed particles are normally known to reduce recrystallization kinetics, having a greater retarding influence on nucleation than on growth (Doherty and Martin, 1984). Out of the available orientations in the cold rolled alloy, the $\{111\}$ texture components should nucleate rather early and therefore will have a long available time for growth before impingement occurs (Hutchinson, 1974). Since the volume fractions of crystallites in the deformed material having such orientations are also the largest, it is therefore no wonder that there will be a predominance of the $\{111\}\langle\mathrm{uvw}\rangle$ components in the recrystallization texture. However, the much higher density of the precipitate particles in the $650^{\circ} \mathrm{C}$ annealed material will tend to hinder the growth of the $\{111\}$ recrystallized grains to a much greater extent than in case of the $800^{\circ} \mathrm{C}$ annealed material. This will tend to make the intensity of the $\{111\}$ texture to have a less sharp value for the $650^{\circ} \mathrm{C}$ annealed material as compared to the $800^{\circ} \mathrm{C}$ annealed material. This is contrary to what has been obtained in the present case.

In view of what has been stated above, it seems that whether the intensity of the $\{111\}$ texture will increase or decrease at the higher recrystallization temperature will depend on the relative strengths of the two factors, namely, the density of precipitate particles present and the martensite (austenite) volume fraction. More is the density of precipitate particles in the ferrite, more will be the hindrance to the rapid growth of the $\{111\}$ oriented grains and therefore less sharp will be the $\{111\}$ texture. Again, an increase in the total volume fraction of martensite in any sample will mean a decrement in the available amount of ferrite and therefore an automatic decrease in the sharpness of the $\{111\}$ texture. It seems that in the present alloy the effect of the second factor is much stronger than the first, as a result of which the $650^{\circ} \mathrm{C}$ annealed material exhibits a sharper $\{111\}$ texture as compared to the $800^{\circ} \mathrm{C}$ annealed sample. 


\section{CONCLUSION}

1. Four different dual phase structures are produced by the following two different kinds of heat treatment cycles, $\mathrm{AC} / \mathrm{WQ}$ and $\mathrm{WQ} / \mathrm{WQ}$, and by a subsequent intercritical annealing at $750^{\circ} \mathrm{C}$ and $810^{\circ} \mathrm{C}$.

2 . The cold rolled materials show a reasonably strong $\langle 111\rangle \| N D$ fibre texture along with a weak $\{11,11,4\}$ fibre and a rather weak and incomplete $\{337\}$ fibre.

3. The recrystallization textures are very similar to the ones for the corresponding deformed materials, with the difference that the intensities of the texture components get reduced in the former. The intensities of the $\{111\}\langle\mathrm{uvw}\rangle$ components have been found to be consistently higher for the materials recrystallized at the lower temperature of $650^{\circ} \mathrm{C}$ as compared to the materials recrystallized at the higher temperature of $800^{\circ} \mathrm{C}$. No perfect fibre with respect to the orientations $\{11,11,4\}\langle u v w\rangle$ and $\{337\}\langle u v w\rangle$ are noticed in the recrystallized samples.

4. The similarity between the deformation and recrystallization textures indicate that the recrystallized grains might have been formed in-situ from cold deformed regions having the same or nearly the same crystallographic orientations.

5. A high intensity of $\{111\}$ texture is found to be associated with a high value of the Lankford parameter, $r$.

\section{ACKNOWLEDGEMENT}

The authors are grateful to Dr. U. V. Schlippenbach of the Institut für Metallkunde in R.W.T.H. Aachen, West Germany for generating O.D.F.'s from the texture samples using a Lücke texture goniometer.

\section{References}

Alam, R., Mengelberg, H. D. and Lücke, K. (1967). Z Metallkunde, 58, 867.

Bunge, H. J. and Vlad, C. M. (1981). Proceedings of the 6th International Conference on Textures, Tokio, 2, 649, Tokyo: Iron and Steel Institute of Japan.

Bunge, H. J., Vlad, C. M. and Kopp, H. (1984). Archiv Für Eisenhüttenwesen, 55, 163.

Cullity, B. D. (1978). Elements of $X$-ray Diffraction, 2nd edn, 308, London: Addison-Wesley.

Dillamore, I. L. and Katoh, H. (1974). Metal Science, 8, 73.

Doherty, R. D. and Martin, J. W. (1964).Transactions, American Society for Metals, $57,874$.

Hu, H. (1980). Texture of Crystalline Solids, 4, 13.

Hutchinson, W. B. (1974) Metal Science, 8, 185.

Hutchinson, W. B. and Dillamore, I. L. (1979). Metallurgia, 5, 257.

Kobbe, U. and Schuon, H. (1973). Siemens Zeitschrift, 47, 119.

Mishra, S. and Därmann, C. (1982) International Metals Reviews, 27, 6, 307.

Ray, R. K. (1984). Scripta Metallurgica, 11, 1211.

Ray, R. K. (1985). Journal of Materials Science Letters, 4, 67.

Schulz, L. G. (1949). Journal of Applied Physics, 20, 1030. 